\title{
Prophylactic effect of Amiodarone and in combination with Vitamin $C$ in reducing atrial fibrillation after coronary artery bypass
}

\author{
Alireza Kamali (1), Samira Yavari (2), Bijan Yazdi (1), Alireza Rostami (2) \\ (1)Department of Anesthesiology and Critical Care, Arak University of Medical Sciences, Arak, \\ Iran ;(2)Department of Cardiovascular Surgery, Arak University of Medical Science, Arak, Iran. \\ This article is distributed under the terms of the Creative Commons Attribution Noncommercial License (CC BY-NC 4.0) which permits \\ any noncommercial use, distribution, and reproduction in any medium, provided the original author(s) and source are credited.
}

\begin{abstract}
Atrial fibrillation (AF) is the most common arrhythmia following cardiac surgery, leading to hemodynamic impairment and increased mortality and morbidity after coronary artery bypass grafting (CABG) and increases hospitalization. Due to the antioxidant and anti-inflammatory effects of vitamin $C$ as well as the antiarrhythmic effect of amiodarone in reducing the incidence of atrial fibrillation after coronary artery bypass grafting, we decided to compare and evaluate the prophylactic effect of amiodarone alone and in combination with vitamin $\mathrm{C}$ in controlling this complication. In this double-blind clinical trial, patients were divided into two equal groups of amiodarone (300 mg amiodarone bolus during 20-30 minutes) and amiodarone + vitamin $\mathrm{C}$ (150 mg amiodarone and 2g vitamin C combination). Each group included 42 patients. All data were analyzed by SPSS 19 software and statistical tests of ANOVA, Chi-square and Repeated Measure. There was a significant difference between the two groups of amiodarone and amiodarone+vitamin $\mathrm{C}$ (p-value $=0.01$ ) and the mean incidence of AF in the amiodarone +vitamin C group was significantly lower than that of amiodarone alone. Other arrhythmias were also lower in the amiodarone +vitamin $\mathrm{C}$ group than in the amiodarone group alone. The use offibrillation after CABG compared with prophylactic amiodarone alone, but did not have a significant effect on decreasing ICU stay(discharge) and duration of hospitalization.
\end{abstract}

Keywords: Amiodarone; atrial fibrillation; prophylaxis; vitamin C.

Eur J Transl Myol 31 (3):8981, 2021 doi: 10.4081/ejtm.2021.8981

Coronary artery disease (CAD) is one of the leading causes of death worldwide. Patients with CAD require coronary artery revascularization along with other medical treatments. Coronary artery bypass grafting (CABG) is a common Interventional surgery at the endstages of coronary artery occlusion disease. Although $\mathrm{CABG}$ is an effective procedure, it may have some complications during and after surgery. ${ }^{1}$ Atrial fibrillation is the most common arrhythmia following cardiac surgery, which occurs in about one third of patients after CABG. ${ }^{2}$ It is a common arrhythmia with various causes, clinical manifestations and treatment options. We can use clinical signs such as increase heart rate, hypotension, irregular heart beat and also ECG, monitoring \& Holter-monitoring (24 hour) for diagnosis of atrial fibrillation (AF). Ideally, treatment of atrial fibrillation involves three stages of evaluation: analysis of underlying cause, control of arrhythmia with reduction of thromboembolic risk, and ultimately, conversion of arrhythmia to normal sinus rhythm. ${ }^{3}$ Postoperative AF is most commonly seen within the first 5 days after surgery, ${ }^{4}$ but it peak within the first 48 hoursin case of open heart surgery, indicating the need for postoperative monitoring. ${ }^{5}$ CAD increases morbidity and mortality after coronary artery bypass surgery, increasing length of stay in intensive care units and hospitalization. ${ }^{6}$ Several factors have been identified in the incidence of postoperative CABG AF, including age, left ventricular failure, previous history of $\mathrm{AF}$, chronic obstructive pulmonary disease (COPD), myocardial infarction, left ventricular size, $\beta$-blocker history, cross-clamp time during surgery and CPB time. ${ }^{7}$ Treatments to prevent atrial fibrillation include the use of $\beta$-blockers, amiodarone, anti-inflammatory drugs, statins, and fatty acids. ${ }^{8}$ Amiodarone is a unique drug that belongs to the class 3 antiarrhythmic agents. It has been used to treat supraventricular, ventricular arrhythmias, and dysrhythmias associated with acute myocardial infarction. Intravenous (low dose) or oral dosing for 3 to 5 days before surgery as well as after coronary artery bypass surgery reduced incidence of atrial fibrillation. ${ }^{4}$ One of the vitamins mentioned in the physiopathological mechanism of AF is vitamin $\mathrm{C}$, which by its anti- 


\section{Atrial fibrillation}

Eur J Transl Myol 31 (3):8991, 2021 doi: 10.4081/ejtm.2021.8991

inflammatory and antioxidant role prevents the formation of inflammation and oxidative stress. ${ }^{9}$ Vitamin $\mathrm{C}$ as a water-soluble antioxidant, in addition to the role of free radicals scavenging, helps to reduce other antioxidants such as vitamin $\mathrm{E}$ and can be useful in reducing the incidence of postoperative atrial fibrillation. ${ }^{10}$ Due to the antioxidant and anti-inflammatory effects of Vitamin C as well as the antiarrhythmic effect of amiodarone in reducing the incidence of atrial fibrillation after coronary artery bypass, we decided to compare the prophylactic effect of amiodarone alone and in combination with vitamin C.

\section{Materials and Methods}

This study is a randomized clinical trial in which patients undergoing coronary artery bypass grafting referring to Amiralmomenin Hospital of Arak (Iran) were divided into two equal groups, Amiodarone and Amiodarone + Vitamin C, using the cubalrandomized method. All of the patients were initially informed about the study and the absence of complications and were randomly entered into the study after obtaining informed consent.

Inclusion criteria:

1. Patients candidate for elective CABG

2. ASA Class 2 and 3

3. No drug allergy to amiodarone

4. Surgery performed by a surgeon

5. Duration of surgery 4 to 6 hours

Exclusion criteria:

1. Use of heart pump 2 times during surgery

2. All patients who died during surgery

3. All patients who require pump balloons after removal from the heart pump

Patients received pre-medication $5 \mathrm{mg}$ of oxasepam the night before surgery and 3 to $5 \mathrm{mg}$ of IV morphine and 15 to $25 \mathrm{mg}$ of promethazine in the morning and then entered the operating room. After entering the operating room for all of them 3 to 5 cc per kg of weight, crystalloid was given to compensate for CVE. Patients were assigned to complete monitoring, including SPO2, NIBP, ECG, PR, after being placed on the operating room bed. Then, each patient received 1 to 2 cc fentanyl from the insertion arterial line for IBP monitoring. Arterial line was inserted from the non-dominant radial artery by needle 20 and attached to the monitoring. After arterial line insertion and complete monitoring, patients were ready for anesthesia induction. Patients in the amiodarone group received $300 \mathrm{mg}$ of amiodarone bolus during 10-20 minutes after arterial line preparation and in the second group (amiodarone + vitamin C) combination of $150 \mathrm{mg}$ amiodarone and $2 \mathrm{~g}$ vitamin $\mathrm{C}$ were given. The drugs were prepared by the anesthesiologist in the special syringes and provided to the project assistant. The project assistant was not aware of the type of drugs and groups of study and was therefore blind to the prescription drug study. All patients were then given 5 to 10 microgram $/ \mathrm{kg}$ of body weight, sufentanil, $0.1 \mathrm{mg} / \mathrm{kg}$ midazolam and 10 to $12 \mathrm{mg}$ pavlone (pancreonium) induction, then intubated. Patients were then prepared to receive a $\mathrm{CV}$ line from the jugular vein. After inserting the $\mathrm{CV}$ line (triluminal) from the right internal jugular vein, anesthetic preservatives including relaxants, opiates, benzodiazepines and anesthetics (propofol) were administered to patients with total IV anesthesia. Finally, surgery was performed after the sternum incision and the patients underwent a heart pump to perform coronary artery bypass grafting. Then, according to the condition and stability of hemodynamics, patients were removed from the cardiopulmonary pump after coronary grafts. After detachment from the cardiopulmonary pump in case of stable condition and hemodynamics of patients, intubated with stable hemodynamics were admitted to ICU open heart. Then, in the ICU, for the first group of patients after the bolus dose, within the 24 hours (after surgery) amiodarone was infused in the first 6 hours, $1 \mathrm{mg} / \mathrm{kg}$ and $0.5 \mathrm{mg} / \mathrm{kg}$ in the next 18 hours (they received amiodarone according to $\mathrm{mg} / \mathrm{kg}$ body weight). In the second group, in addition to receiving the dose of amiodarone infusion, as in the first group, 1 gr of vitamin C was administered to patients during 24 hours. Both groups of patients received amiodarone on the infusion pump for 24 hours and in the amiodarone + vitamin C group, $1 \mathrm{~g}$ vitamin $\mathrm{C}$, equivalent to 2 vials of $5 \mathrm{cc}$ vitamin C was given slowly IV over 24 hours and in the amiodarone group (group 1), for observing blindness the same amount (2 vials of $5 \mathrm{cc}$ ) of normal saline were given slowly. Syringes containing vitamin $\mathrm{C}$ and normal saline were prepared by the anesthesiologist in charge of the plan and provided to the open heart ICU nurse. The syringes containing the desired solutions were identical in volume and appearance and were equivalent to 2 vials of 5 сc. The open heart ICU nurse responsible for the infusion of vitamin $\mathrm{C}$ was not aware of the type of drugs. For all patients, a questionnaire containing demographic information including age, sex, number of grafts, length of stay in the ICU, as well as the arrhythmia incidence of $\mathrm{AF}$ and other arrhythmias was completed by the intern responsible for the trial and if arrhythmia was included AF, VT, PSVT, VF were recorded in each of the study groups in a trial questionnaire and patients underwent routine antiarrhythmic treatment. Patients under study in the open heart ICU continued for 72 hours after surgery with the maximum length of stay in the open heart ICU and were recorded in the questionnaires if $\mathrm{AF}$ and other arrhythmias occurred

Sample size:

$$
N=\frac{\left(Z_{1-\frac{\alpha}{2}}+Z_{1-\beta}\right)^{2}\left[\mathrm{p}_{1}\left(1-\mathrm{p}_{1}\right)^{2}+\mathrm{p}_{2}\left(1-\mathrm{p}_{2}\right)^{2}\right]}{\left(\mathrm{p}_{1}-\mathrm{p}_{2}\right)^{2}}
$$

$P_{2}=0.4$ 


\section{Atrial fibrillation}

Eur J Transl Myol 31 (3):8991, 2021 doi: 10.4081/ejtm.2021.8991

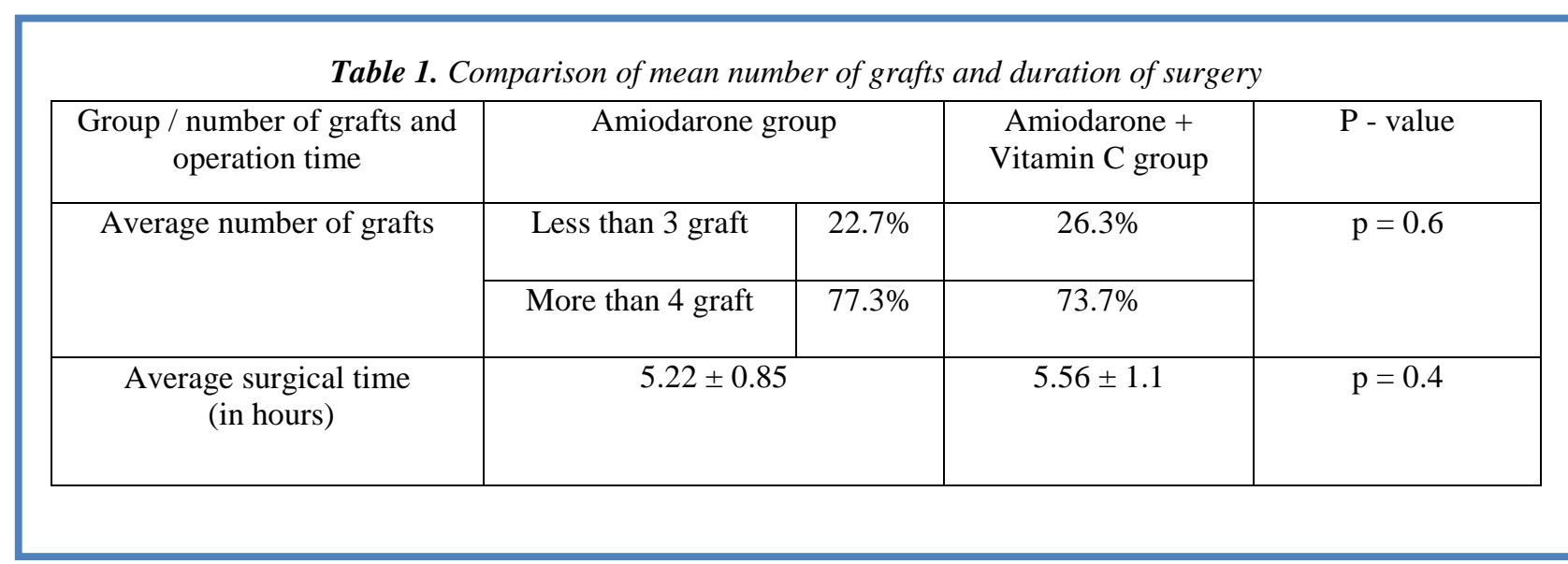

$Z_{1-\frac{\alpha}{2}}=1.69$

$\mathrm{P}_{1}=0.15$

$Z_{1-\beta}=1.28$

The total sample was 84 patients divided into two groups.

\section{Data analysis}

After data collection and entering into SPSS-19 statistical software, the data were analyzed using ANOVA, Chisquare and Repeated measure statistical tests. Finally, the results are expressed as tables.

\section{Ethical considerations}

In this study, the names and profile of confidential persons were recorded and no cost was imposed on the patient's family. Completion of the questionnaire was done with patient consent and patients' written consent was obtained. At all stages of research, including proposal writing, sample collection, and data analysis, researchers were required to adhere to the ethics of research approved by the Ministry of Health and the Helsinki Declaration.

\section{Results}

84 patients were included in the study based on inclusion and exclusion criteria. The mean age of the candidate patients (CABG) in the amiodarone and amiodarone + vitamin $C$ groups was $64.2 \pm 3.8$ and $63.7 \pm 4.1$ respectively, basis of gender $78.2 \%$ and $76.6 \%$ were male and $21.8 \%$ and $23.4 \%$ were female, respectively. Results showed no significant difference between the two groups in terms of mean age $(p-$ value $=0.3)$ and sexual frequency ( $p$ - value $=0.6$ ) and mean age of both groups was 64 years and frequency of male patients in both groups was approximately $77 \%$.

The mean number of grafts and duration of surgery in the candidate patients (CABG) was compared between the two groups in Table 1 and the results showed that the mean number of grafts $(p-$ value $=0.6)$ and Mean duration of surgery $(p-$ value $=0.4)$ were not significantly different. The average number of grafts in both groups for 4 grafts or more; was $75 \%$ and the mean duration of surgery was approximately 3-5 hours in both groups.

\begin{tabular}{|c|c|c|c|c|}
\hline Group / incidence of AF and other & \multicolumn{2}{|c|}{ Amiodarone group } & Amiodarone + & $\mathrm{p}$ - value \\
\hline \multirow[t]{2}{*}{ Mean postoperative AF incidence } & $\begin{array}{c}\mathrm{AF} \\
\text { incidence }\end{array}$ & $13.1 \%$ & $9.2 \%$ & \multirow[t]{2}{*}{$\mathrm{p}=0.01$} \\
\hline & $\begin{array}{c}\text { Without } \\
\text { AF }\end{array}$ & $86.9 \%$ & $90.8 \%$ & \\
\hline \multirow{2}{*}{$\begin{array}{l}\text { Average incidence of other postoperative } \\
\text { arrhythmias }\end{array}$} & $\begin{array}{l}\text { Arrhythmia } \\
\text { incidence }\end{array}$ & $13.1 \%$ & $8.7 \%$ & \multirow[t]{2}{*}{$p=0.01$} \\
\hline & $\begin{array}{l}\text { Without } \\
\text { arrhythmia }\end{array}$ & $86.9 \%$ & $91.3 \%$ & \\
\hline
\end{tabular}


Atrial fibrillation

Eur J Transl Myol 31 (3):8991, 2021 doi: 10.4081/ejtm.2021.8991

Table 3. Comparison of mean bypass time and mean aortic cross-clamp time

\begin{tabular}{|c|c|c|c|}
\hline $\begin{array}{c}\text { Group / Mean bypass time } \\
\text { and aortic clamp }\end{array}$ & Amiodarone group & $\begin{array}{c}\text { Amiodarone }+ \\
\text { Vitamin C group }\end{array}$ & $\mathrm{p}$ - value \\
\hline Average bypass time (min) & $100.1 \pm 10.1$ & $95.8 \pm 9.8$ & $\mathrm{p}=0.4$ \\
\hline $\begin{array}{c}\text { Mean aortic cross-clamp time } \\
\text { (min) }\end{array}$ & $8.3 \pm 51.6$ & $7.6 \pm 48.8$ & $\mathrm{p}=0.6$ \\
\hline
\end{tabular}

Table 2 compares the mean incidence of atrial fibrillation (AF) and the mean incidence of other postoperative arrhythmias in patients (CABG) in the two groups of amiodarone and + vitamin $\mathrm{C}$. The results showed a significant difference $(p-$ value $=0.01)$ between the two groups regarding the mean incidence of postoperative $\mathrm{AF}$ (AF post-CABG) and atrial fibrillation (AF) was significantly lower in the amiodarone + vitamin $\mathrm{C}$ group than in the amiodarone group alone. Also, the mean incidence of other arrhythmias after surgery was significantly different $(\mathrm{p}$ - value $=0.01)$ and the mean of other arrhythmias were significantly lower in the amiodarone + vitamin C group than the amiodarone group alone.

The mean incidence of AF during the 24 hours postoperatively was $1.2 \pm 0.28$ in the patients in the amiodarone group and $1.3 \pm 0.34$ in the amiodarone+ vitamin C group. No significant difference was seen in almost all patients in the two groups with atrial fibrillation and the incidence of it was 1.2 times during the 24 hours after surgery $(p-$ value $=0.6$ ).

The mean duration of ICU admission in the amiodarone and amiodarone+vitamin C groups was $6.4 \pm 0.89$ and $6.2 \pm 1.1$ days, respectively. As well as the mean hospitalization in the candidate patients (CABG) in the two groups of amiodarone and amiodarone+vitamin $\mathrm{C}$ were reported $12.7 \pm 2.4$ and $13.1 \pm 1.2$ days, respectively. There was no significant difference in open heart ICU admission and in both groups the duration of ICU stay was 6 days. There was no significant difference in mean hospital stay between the two groups and mean hospitalization in the two groups was approximately 12.5 days (p -value:0.4, p - value:0.6).

Average mortality rate and the use of electroconvulsive therapy in the patients (CABG Candidates) in both groups was reported zero, so no significant difference was seen between the two groups and mortality and shock use were not observed in the two groups ( $\mathrm{p}$-value $\geq 0.5)$.

Table 3 compares the mean bypass time and mean time of aortic cross-clamp in candidate patients (CABG) in the two groups of amiodarone and amiodarone+vitamin C. The results showed that there was no significant difference between the two groups in mean bypass time $(\mathrm{p}-$ value $=0.4)$ and mean aortic clamp time $(\mathrm{p}-$ value $=0.6$ ) and in both groups the mean bypass time was approximately 95-96 minutes and the aortic cross-clamp duration was approximately 50 minutes.

\section{Discussion}

Atrial fibrillation is defined as a supraventricular tachyarrhythmia characterized by uncoordinated atrial activity and subsequent mechanical failure of the atrium. ${ }^{11}$ Atrial fibrillation is the most common cardiac arrhythmia that has a direct relationship with age. ${ }^{12}$ Statistics show that about one-third of hospitalizations due to heart disease is from AF disease, which has risen $66 \%$ over the past 20 years. This increase is due to an aging population, an increase in the prevalence of chronic heart disease, and an increase in diagnostic ability due to the development of equipment. ${ }^{13}$ As a result, we decided to investigate the prophylactic effect of amiodarone and the combination of amiodarone with vitamin $\mathrm{C}$ in reducing the incidence of atrial fibrillation after coronary artery bypass grafts. Results of this study showed that in the amiodarone+ vitamin $\mathrm{C}$ group, the incidence of atrial fibrillation after coronary artery bypass was significantly decreased and other arrhythmias postoperatively were less than the amiodarone group. In a similar study by Kojuri et al. (2009) on 240 Iran patients with coronary artery bypass graft, ${ }^{14}$ they found that both propranolol and amiodarone were effective in reducing the incidence of atrial fibrillation after coronary artery bypass grafting but Amiodarone or combination of amiodarone with propranolol as a prophylactic drug was more effective than propranolol alone in reducing the incidence of atrial fibrillation after coronary artery bypass. The results of that study are consistent with our because in our study amiodarone also reduced the incidence of atrial fibrillation after coronary artery bypass grafting. In a similar study by Stanger et al, in 2014 in Australia in 75 patients with coronary artery bypass grafting, the patients were divided into 4 groups, first group treated with vitamin $\mathrm{E}$ and $\mathrm{C}$, second group treated with n3PUFA (n3polyunsaturated fatty acid), the third group treated with combined vitamin $\mathrm{C}, \mathrm{E}, \mathrm{n} 3 \mathrm{PUFA}$ and the fourth group treated with placebo. The results of this study indicate that the use of antioxidant vitamins reduces the incidence of atrial fibrillation after coronary artery bypass grafting. ${ }^{15}$ The results are also consistent with our study because in our study, vitamin $\mathrm{C}$ led to a further reduction in atrial fibrillation after coronary artery bypass grafting. In another study carried out between 2016-2017 in Iran on 146 patients with coronary artery bypass graft, Kamali et al., ${ }^{16}$ compared the prophylactic effect of amiodarone and metoral on reducing the incidence of 


\section{Atrial fibrillation}

Eur J Transl Myol 31 (3):8991, 2021 doi: 10.4081/ejtm.2021.8991

atrial fibrillation after coronary artery bypass grafting. The results of this study indicated that metoral significantly had a greater effect on decreasing the incidence of atrial fibrillation after coronary artery bypass grafting than amiodarone. The results of this study are partly consistent with our study because in this study amiodarone also had an effect on reducing the incidence of atrial fibrillation after coronary artery bypass grafting, but the metoral was more effective. In our study, amiodarone was also effective in reducing atrial fibrillation after coronary artery bypass grafting, whereas the use of vitamin $\mathrm{C}$ along with it had a greater effect. In a study by Harling et al. (2017) in London on 567 patients undergoing cardiac surgery, they investigated the antiarrhythmic effect of antioxidant vitamins in cardiac surgery. ${ }^{17}$ The results of this study showed that the combination of two antioxidants $\mathrm{E}$ and $\mathrm{C}$ in order to prophylaxis significantly reduced the incidence of atrial fibrillation after coronary artery bypass and reduced their hospitalization. ${ }^{17}$ The results of this study were somewhat consistent with our study because in our study vitamin $\mathrm{C}$ had also increased the antiarrhythmic effect of amiodarone and its effect on reducing the incidence of atrial fibrillation after coronary artery bypass but in our study use vitamin $\mathrm{C}$ had no effect on ICU stay and hospitalization compared to the nonvitamin $C$ group and was not consistent with the above study. In conclusion our data show that the use of vitamin $\mathrm{C}$ in combination with amiodarone significantly reduces the incidence of atrial fibrillation after coronary artery bypass surgery compared to prophylactic amiodarone alone, but it had no significant effect on decreasing ICU length of stay and hospitalization. For other similar studies larger sample size and evaluation of other drugs affecting Post CABG AF is recommended.

\section{List of acronyms}

AF - Atrial fibrillation

ASA - American Society of Anesthesiologists

CABG - Coronary artery bypass graft

CAD - Coronary artery disease

COPD - Chronic obstructive pulmonary disease

CPB - Cardiopulmonary bypass

$\mathrm{CV}$ - Central venous

CVE - Common Vulnerabilities and Exposures

ECG - Electrocardiogram

ICU - Intensive care unit

NIBP - Non-invasive blood pressure

PSVT - Paroxysmal supraventricular tachycardia

RR - Respiration Rate

SpO2 - Pulse oximetry

VF - Ventricular fibrillation

VT - ventricular tachycardia

\section{Authors contributions}

AK,SY,BY,and AR conceived the study, analyzed the data, wrote the paper and helped to editing the manuscript.
Acknowledgments None

\section{Funding}

No funding was obtained for this project.

\section{Conflict of Interest}

The authors declare no conflicts of interest.

\section{Ethical Publication Statement}

We confirm that we have read the Journal's position on issues involved in ethical publication and affirm that this report is consistent with those guidelines.

\section{Corresponding Author}

Alireza Rostami, Department of Cardiovascular Surgery, Arak University of Medical Science, Arak, Iran.

ORCID iD: 0000-0002-0445-729X

Alireza Rostami: Dr_ar_rostami@yahoo.com

E-mails and ORCID iD of co-authors

Alireza Kamali: Alikamaliir@yahoo.con

ORCID iD: 0000-0003-0698-340X

Samira Yavari: s.yavari.dr@gmail.com

ORCID iD: 0000-0002-4364-1102

Bijan Yazdi: yazdi.b@arakmu.ac.ir

yazdibijan@hotmail.com

ORCID iD:0000-0001-5304-9957

\section{References}

1. Mirmansoori A, Farzi F, Sedighinejad A, Imantalab V, Mohammadzadeh A, Atrkar Roushan Z, Ghazanfar Tehran S, Nemati M, Dehghan A. The Effect of Desmopressin on the Amount of Bleeding in Patients Undergoing Coronary Artery Bypass Graft Surgery with a Cardiopulmonary Bypass Pump After Taking Anti-Platelet Medicine. Anesth Pain Med. 2016 Jul 26;6(5):e39226. doi: 10.5812/aapm.39226.

2. Habibollahi P, Jam SH, Vahdati SS, Baghi HM, Amiri H. Amiodaron in atrial fibrillation: post coronary artery bypass graft. World J Emerg Med. 2016;7(4):250-254. doi: 10.5847/wjem.j.19208642.2016.04.002.

3. Lip GY, Zarifis J, Watson RD, Beevers DG. Physician variation in the management of patients with atrial fibrillation. Heart. 1996 Feb;75(2):2005. doi: 10.1136/hrt.75.2.200.

4. Buckley MS, Nolan PE Jr, Slack MK, Tisdale JE, Hilleman DE, Copeland JG. Amiodarone prophylaxis for atrial fibrillation after cardiac surgery: meta-analysis of dose response and timing of initiation. Pharmacotherapy. 2007 Mar;27(3):360-8. doi: 10.1592/phco.27.3.360.

5. Tiryakioglu O, Demirtas S, Ari H, Tiryakioglu SK, Huysal K, Selimoglu O, Ozyazicioglu A. Magnesium sulphate and amiodarone prophylaxis for prevention of postoperative arrhythmia in coronary by-pass operations. J Cardiothorac Surg. 2009 Feb 20;4:8. doi: 10.1186/1749-8090-4-8. 


\section{Atrial fibrillation}

Eur J Transl Myol 31 (3):8991, 2021 doi: 10.4081/ejtm.2021.8991

6. Budeus M, Hennersdorf M, Perings S, Röhlen S, Schnitzler S, Felix O, Reimert K, Feindt P, Gams E, Lehmann N, Wieneke H, Sack S, Erbel R, Perings C. Amiodarone prophylaxis for atrial fibrillation of high-risk patients after coronary bypass grafting: a prospective, double-blinded, placebo-controlled, randomized study. Eur Heart J. 2006 Jul;27(13):1584-91. doi: 10.1093/eurheartj/ehl082. Epub 2006 Jun 7.

7. Jalalian R, Ghafari R, Ghazanfari P. Comparing the therapeutic effects of carvedilol and metoprolol on prevention of atrial fibrillation after coronary artery bypass surgery, a double-blind study. Int Cardiovasc Res J. 2014 Sep;8(3):111-5. Epub 2014 Sep 1.

8. Moludi J, Keshavarz S, Mohammad Javad H, Rahimi Frooshani A, Sadeghpour A, Salarkia S, Gholizadeh F. Coenzyme Q10 effect in prevention of atrial fibrillation after Coronary Artery Bypass Graft: double-blind randomized clinical trial. Tehran Univ Med J. 2015; 73: 79-85.

9. Samadikhah J, Golzari SE, Sabermarouf B, Karimzadeh I, Tizro P, Mohammad Khanli H, Ghabili K. Efficacy of Combination Therapy of Statin and Vitamin C in Comparison with Statin in the Prevention of Post-CABG Atrial Fibrillation. Adv Pharm Bull. 2014;4(1):97-100. doi: 10.5681/apb.2014.015. Epub 2013 Dec 23.

10. Bagshaw SM, Galbraith PD, Mitchell LB, Sauve R, Exner DV, Ghali WA. Prophylactic amiodarone for prevention of atrial fibrillation after cardiac surgery: a meta-analysis. Ann Thorac Surg. 2006 Nov;82(5):1927-37. doi: 10.1016/j.athoracsur.2006 .06 .032 .

11. Calkins H, Kuck KH, Cappato R, Brugada J, Camm AJ, Chen SA, Crijns HJ, Damiano RJ Jr, Davies DW, DiMarco J, Edgerton J, Ellenbogen K, Ezekowitz MD, Haines DE, Haissaguerre $\mathrm{M}$, Hindricks G, Iesaka Y, Jackman W, Jalife J, Jais P, Kalman J, Keane D, Kim YH, Kirchhof P, Klein G, Kottkamp H, Kumagai K, Lindsay BD, Mansour M, Marchlinski FE, McCarthy PM, Mont JL, Morady F, Nademanee K, Nakagawa H, Natale A, Nattel S, Packer DL, Pappone C, Prystowsky E, Raviele A, Reddy V, Ruskin JN, Shemin RJ, Tsao HM, Wilber D. 2012 HRS/EHRA/ECAS Expert Consensus Statement on Catheter and Surgical Ablation of
Atrial Fibrillation: recommendations for patient selection, procedural techniques, patient management and follow-up, definitions, endpoints, and research trial design. Europace. 2012 Apr;14(4):528-606. doi: 10.1093/europace/eus027. Epub 2012 Mar 1.

12. Davis RC, Hobbs FD, Kenkre JE, Roalfe AK, Iles R, Lip GY, Davies MK. Prevalence of atrial fibrillation in the general population and in highrisk groups: the ECHOES study. Europace. 2012 Nov;14(11):1553-9. doi: 10.1093/europace/eus087. Epub 2012 Apr 5.

13. Friberg J, Buch P, Scharling H, Gadsbphioll N, Jensen GB. Rising rates of hospital admissions for atrial fibrillation. Epidemiology. 2003 Nov;14(6):666-72. doi: 10.1097/01.ede.0000091649.26364.c0.

14. Kojuri J, Mahmoodi Y, Jannati M, Shafa M, Ghazinoor M, Sharifkazemi MB. Ability of amiodarone and propranolol alone or in combination to prevent post-coronary bypass atrial fibrillation. Cardiovasc Ther. 2009 Winter;27(4):253-8. doi: 10.1111/j.17555922.2009.00100.x.

15. Stanger O, Aigner I, Schimetta W, Wonisch W. Antioxidant supplementation attenuates oxidative stress in patients undergoing coronary artery bypass graft surgery. Tohoku J Exp Med. 2014 Feb;232(2):145-54. doi: 10.1620/tjem.232.145.

16. Kamali A, Sanatkar A, Sharifi M, Moshir E. Evaluation of amiodarone versus metoprolol in treating atrial fibrillation after coronary artery bypass grafting. Interv Med Appl Sci. 2017 Jun;9(2):51-55. doi: 10.1556/1646.9.2017.2.11.

17. Harling L, Rasoli S, Vecht JA, Ashrafian H, Kourliouros A, Athanasiou T. Do antioxidant vitamins have an anti-arrhythmic effect following cardiac surgery? A meta-analysis of randomised controlled trials. Heart. 2011 Oct;97(20):1636-42. doi: 10.1136/heartjnl-2011-300245. Epub 2011 Aug 23.

Submission: March 24, 2020

Revision received: April 07, 2020

Accepted for publication: January 25, 2021 